\title{
COPIM
}

\section{COPIM Community Governance Workshop Recap: Part 1}

Sam Moore ${ }^{1}$, Janneke Adema ${ }^{1}$

${ }^{1}$ Centre for Postdigital Cultures, Coventry University

Published on: May 22, 2020

DOI: $10.21428 / 785 a 6451.6 a 3 a 2 c a 2$

License: Creative Commons Attribution 4.0 International License (CC-BY 4.0). 
On May 1, 2020, the COPIM project hosted a half-day workshop focused on community governance. COPIM intends to set up an open, community-led governance system for its infrastructures and processes, a structure that we want to develop together with the community of stakeholders that will be involved in the project more broadly, such as academics, publishers, librarians, researchers, and knowledge managers. This community workshop brought together governance experts, key stakeholders in OA book publishing, and representatives from allied large community-led projects, to collaboratively explore what the governance procedures of COPIM's open publication ecosystem for monographs should look like and to begin thinking about developing models to sustain the governance of the infrastructure as a community-based OA service organization.

Though the workshop was originally supposed to be held in Santa Barbara, with help from colleagues at UCSB library, Coventry University and the ScholarLed consortium we were able to move this to an online meeting across a number of time zones. Participants of the meeting were: Janneke Adema (Coventry University), Arianna Becerril García (AmeliCA), Leslie Chan (University of Toronto), Joe Deville (Lancaster University, and Mattering Press), Kathleen Fitzpatrick (Michigan State University), Elli Gerakopoulou (Lancaster University), Dave S. Ghamandi (University of Virginia), Alan Grosenheider (University of California, Santa Barbara), Chris Land (Anglia Ruskin University), Stuart Lawson (Edinburgh Napier University), Catherine Mitchell (California Digital Library), Samuel Moore (Coventry University), Cameron Neylon (Curtin University), Florence Piron (éditions science et bien commun), Reggie Raju (University of Cape Town), Dan Rudman (punctum books), Nick Shockey (SPARC), Katherine Skinner (Educopia Institute), Tobias Steiner (Coventry University), and Lidia Uziel (UCSB Library).

Within the two posts that follow, we hope to present some of the discussion that went on in the workshop, most notably around two key questions:

1. What does good governance mean? and

2. Who is COPIM's community?

The first of these posts will summarise the discussions we had around the first question. In small breakout groups of 5-6 people, participants were asked to draw on their own experiences on what good governance means to them. 


\section{Situatedness}

A number of themes emerged from this discussion that resonate with the blogpost we shared a few weeks ago, most notably around the situated nature of governance. Participants noted that good governance is context-specific in providing accountability to a specific community or range of communities (more on community in part 2). Good governance will designate decision-making powers within a community based on its norms, practices and the kind of resources being managed. Governance was also associated with the ability to promote equity and fairness in an organisation, a level of formality that is required to ensure that the organisation works for all people participating in it. Katherine Skinner also noted that this situatedness makes it difficult to assess what good governance actually is, simply because there are so many different variables at play and priorities within different kinds of organisation. Chris Land added to this point with the idea that the situatedness of an organisation influences the kinds of normalised governance models in a particular field (e.g., an advisory board is an expectation of many scholarly communication institutions), making governance inseparable from an organisation's strategy and position. Situatedness thus confers certain expectations about governance that may lead to organisations relying on existing models rather than experimenting with new structures.

\section{Formality}

The formality of governance was also a source of contention in the discussions. Many of the participants are working on small, community-led scholarly communication organisations that are somewhat resistant to formality. For example, Florence Piron described governance as something that might 'come later' but that her attention is currently focused on the labour of love inherent in producing books. This means that designers of good governance are faced with the issue of who actually gets to design these systems of governance, especially when multiple stakeholders are involved but there is an imbalance of labour and tacit ownership between the participants. Put simply, many open projects rely on the hard work of 'benevolent dictators' to sustain their operations - as the media theorist Nathan Schneider explored in a recent article and this makes defining adequate systems of governance very tricky. Stuart Lawson emphasised that this imbalance of labour may also not be about ownership of a project per se, rather that people's time is at a premium and so the burden of governance in horizontal and informal organisations may fall to whoever actually has time or inclination to do the work. 


\section{Process}

Related to this is the idea of governance as a process. Reggie Raju emphasised that governance requires a solid foundation from which the organisation can grow, based on what he termed a 'flexible tenancy' mode of governance that adapts as stakeholders change and organisations develop. It is therefore worth thinking about governance from the outset of a project and continually re-assessing an organisation's processes and assumptions. Joe Deville developed this through the idea that organisational growth and greater financial sustainability necessitate dynamic models as the organisation moves from an informal to a formalised system of governance. For example, it is something of a mixed blessing when an organisation is financially sustainable and increasing its membership because this can work against the informality that might have made the project a success to begin with. Yet the risk is that formalised systems of governance may be a hinderance to the community norms and informal relationships that have developed. Furthermore, as the organisation reaches maturity and self-sufficiency, we might consider how founders can best plan for long-term governance of the project. For Cameron Neylon, good governance actually allows founders to step away from a project or organisation, in the knowledge that the systems are in place to allow it to function smoothly.

\section{Diversity}

Although situatedness is linked with good governance, we must be careful to recognise that situatedness does not lead to homogenisation. Katherine Skinner mentioned the risk that community-led projects rely solely on their private networks in way that may reinforce existing power structures. Many participants mentioned the importance of ensuring diversity within an organisation's governance in order to move beyond these networks and that formalised governance systems are perhaps better for ensuring intentional and democratic approaches to diversity. For example, Dave Ghamandi emphasised the importance of leaders being both accountable and changeable on a rotational basis so that leadership does not belong in the hands of a special group of people.

Related to this is the importance of who has a say and whom is able to participate. While the idea of community and exclusion will be explored in part 2 of this post, it is worth mentioning here that good governance relates to all stakeholders or actors in the network and is able to account for the multitude of relations and ways if working that are on display within an organisation or project. This will require us to account for different linguistic and geographical contexts, as Florence Piron explained. It may also 
require considerations of non-human actors and assemblages rather than just prioritising the human, as Chris Land reminded us. However, as Catherine Mitchell added, it is also necessary to consider the tension between expansive forms of governance and more lightweight forms that permit greater agility. There is a balance to be struck between democratic participation, rules and norms, and simply getting things done: governance has the ability to profoundly shape these issues through both the imposition of rules and the nurturing of diverse cultures.

\section{Final thoughts}

The answers to this question gave us much to think about for the COPIM project. As a multi-stakeholder initiative involving a number of different participants including publishers, librarians, technologists and researchers, COPIM will need to have some level of formality in its system of governance. We must therefore be cognisant of the limitations of formality, its potential to work against agility and the constant need to reassess our systems of governance. There are also important questions of scope and power dynamics to consider: whose voices get heard, how conflict is resolved and how labour is valued. COPIM will be reaching out to a range of stakeholders to understand how we can best include them within our governance systems.

Yet we must also be aware of the limitations of rules and regulations, and look instead to the cultures and norms that underpin good governance. How, for example, do we encourage a culture of trust and generosity within COPIM? Is it enough to assume that because we are all pushing in the same direction that good governance will follow? Many of these issues relate to the communities that are involved with COPIM and the values they hold. The next post will explore some of these issues with respect to the workshop discussion on who COPIM's community is. 